\title{
Penggunaan Budaya Pop Korea dalam Proses Pembelajaran Bahasa Korea bagi Mahasiswa dengan Gaya Belajar Campuran
}

\author{
Ummul Hasanah ${ }^{1}$, Mery Kharismawati ${ }^{2}$ \\ Sekolah Vokasi, Universitas Gadjah Mada ${ }^{1,2}$ \\ ummul.hasanah@ugm.ac.id ${ }^{1}$ \\ mery.kharismawati@ugm.ac.id ${ }^{2}$
}

\begin{abstract}
Many students learn Korean language because they love Korean pop culture such as song, movie, and TV show at the first place. To achieve learning goals, lecturer must match the class activities to students' learning style. The purpose of this research is to find out the effectiveness of Korean pop culture usage in Korean language learning activities. Beside that, to find what kind of class activities gain interest to Korean language learners. By using questionnaire and observation method, it is found that Korean language students like visual learning style and the combination of visual, auditory, and kinesthetic learning style. However, there are also some students who cannot decide their own learning style. With the mixed learning style, students are more flexible to follow learning activities and can adapt easier when learning environment changes. Although most respondents support the use of Korean pop culture in the class activities, some students state their disagreement. The reasons for their disagreement are because they worry that learning atmosphere will be disturbed because the class will be too noisy and they also want to differentiate between learning in the class and enjoying Korean pop culture outside classroom.
\end{abstract}

Keywords: Korean language, Korean pop culture, learning style

\section{INTISARI}

Banyak mahasiswa yang termotivasi untuk belajar bahasa Korea karena mereka tertarik pada budaya pop Korea seperti lagu, drama, dan acara TV Korea. Untuk bisa mencapai tujuan pembelajaran yang diinginkan, dosen harus menyesuaikan kegiatan belajar di kelas dengan gaya belajar dari mahasiswa yang diajar. Penelitian ini bertujuan mengetahui seberapa efektif penggunaan budaya pop Korea untuk menunjang kegiatan pembelajaran bahasa Korea. Selain itu, penelitian juga dilakukan untuk mengetahui kegiatan apa yang seharusnya dilakukan di kelas agar mahasiswa tertarik untuk belajar bahasa Korea. Dengan menggunakan metode angket dan observasi, dapat diketahui bahwa mahasiswa Prodi bahasa Korea menyukai gaya belajar visual dan campuran dari visual, auditori, dan kinestetik, namun ada pula mahasiswa yang belum menemukan gaya belajarnya. Dengan gaya belajar campuran, mahasiswa bisa lebih fleksibel dalam mengikuti kegiatan pembelajaran serta lebih mudah menyesuaikan diri jika lingkungan belajarnya berubah. Walaupun sebagian besar responden mengaku mendukung penggunaan budaya pop Korea dalam proses pembelajaran di kelas, beberapa responden menyatakan ketidaksetujuannya. Beberapa alasan dari ketidaksetujuan tersebut adalah karena mereka khawatir kondisi pembelajaran di kelas menjadi terlalu berisik dan mereka tetap ingin ada batasan antara belajar di kelas dan menikmati budaya pop Korea di luar kelas.

Kata kunci: bahasa Korea, budaya pop Korea, gaya belajar 


\section{PENDAHULUAN}

Untuk mencapai tujuan pembelajaran yang diinginkan, seorang pengajar haruslah memakai media ajar yang sesuai untuk kelas yang diampu. Media ajar tersebut harus disesuaikan dengan kondisi kelas dan kondisi murid-murid yang belajar di kelas. Salah satu hal yang perlu diperhatikan dari para murid tersebut adalah gaya belajarnya. Karena setiap siswa memiliki gaya belajar masingmasing, pengajar perlu tahu mayoritas gaya belajar siswa di kelas tersebut dan membuat kegiatan kelas yang sesuai dengan gaya belajar siswa-siswi di sana.

Kelas bahasa Korea di Program Studi DIII Bahasa Korea, Departemen Bahasa, Seni, dan Manajemen Budaya (DBSMB), Sekolah Vokasi UGM mempunyai banyak mahasiswa yang bersemangat jika diselipkan budaya pop Korea dalam kegiatan pembelajaran di kelas. Budaya pop yang dimaksud bisa dalam bentuk lagu Korea, cuplikan drama Korea, ataupun video klip dari acara TV Korea. Akan tetapi, harus disadari bahwa satu jenis media pembelajaran tidak selalu sesuai dengan gaya belajar semua mahasiswa. Oleh karena itu, melalui penelitian ini, akan dilihat gaya belajar seperti apa yang disukai oleh mahasiswa dan mahasiswi Program Studi D3 Bahasa Korea, Sekolah Vokasi UGM. Setelah mengetahui gaya belajar mereka, akan dilihat apakah penggunaan budaya populer Korea cocok untuk dipakai sebagai kegiatan belajar bahasa Korea. Sebelum lebih jauh menganalisis hasil penelitian, perlu diketahui terlebih dahulu pengertian dari gaya belajar dan budaya populer Korea.

\section{Gaya Belajar}

Menurut pengertiannya, gaya belajar merupakan cara yang konsisten yang dipilih oleh seorang siswa dalam melakukan kegiatan berpikir, menyerap informasi, memproses, dan memahami suatu informasi serta mengingatnya dalam memori. Efektif tidaknya suatu proses pembelajaran akan sangat berhubungan dengan metode pembelajaran dan media pembelajaran yang digunakan guru dengan gaya belajar siswanya (Muhtadi, 2006). Menurut Xu (2011), setiap orang memiliki cara yang berbeda dalam mempelajari bahasa asing karena masing-masing orang memiliki perbedaan latar belakang pendidikan dan budaya, perbedaan kepribadian, serta perbedaan pengalaman belajar. Perbedaan cara belajar ini membawa pada tingkatan keberhasilan yang berbeda pula. Perbedaan cara yang dipilih seseorang untuk belajar disebut dengan "learning style" atau gaya belajar.

Dalam proses belajar mengajar di perguruan tinggi, kualitas proses pembelajaran akan meningkat jika strategi penyampaian pesan pembelajaran yang diterapkan dosen sesuai dengan karakteristik gaya belajar mahasiswa (Muhtadi, 2006). Ketidakpahaman dan ketidaksesuaian gaya belajar siswa dengan cara pendidik mengajar akan menyebabkan gagal dalam proses pembelajaran. Oleh karena itu, seorang pendidik harus mengetahui gaya belajar yang dimilki oleh peserta didik (Syarfuni \& Verawati, 2017).

"The advantage of understanding learning styles is that it helps teachers to design lesson plans to match their students' styles. Matching is especially important when dealing with new or poor learners as they easily become frustrated at this stage of learning" (Akram Awla, 2014).

Dari kutipan tersebut di atas, dapat dipahami bahwa gaya belajar yang bisa ditentukan oleh pembelajar dapat membantu para pengajar untuk mendesain rencana pembelajaran. Rencana pembelajaran tersebut bisa disesuaikan dengan gaya belajar dari para murid. Penyesuaian antara gaya belajar dari pelajar dan desain pengajaran yang dibuat oleh pengajar tersebut sangat penting terutama bagi pembelajar baru atau pembelajar yang tertinggal karena hal ini bisa membantu mereka mengikuti kegiatan pembelajaran di kelas dengan lebih baik. 


\section{Budaya Populer Korea}

Budaya dari Korea Selatan berkembang dengan sangat pesat di seluruh dunia, terutama di Asia karena memiliki unsur budaya yang mirip. Baik itu musik, film, drama, program TV, produk kosmetik hingga gaya hidup ala Korea Selatan mulai dikenal sejak berkembangnya Korean Wave (Rani, 2016). Korean wave atau Korean hallyu yang berarti gelombang budaya Korea yang mengalir ke berbagai negara di dunia bersumber pada budaya populer ( culture) yang diekspor ke berbagai negara di dunia dalam bentuk produk budaya seperti drama televisi, film, musik K-Pop, animasi, dan games. Produk-produk budaya tersebut dinikmati oleh masyarakat luas dari berbagai kalangan dan generasi di seluruh dunia. Produk-produk dari Korea Selatan tersebut memadukan modernitas, teknologi dan tradisi dengan nilai kekeluargaan sehingga dapat diterima oleh banyak penggemarnya. Korea Selatan terus memperluas pengaruh Korean wave ( $K$ Wave) atau gelombang budaya Korea dengan mengekspor lebih banyak drama Korea, program televisi Korea, film Korea, dan musik popular Korea yang sering diistilahkan dengan K-Pop ke berbagai negara di Asia, Amerika, dan Eropa (Suryani, 2015).

Para pelaku industri hiburan Korea dapat dikatakan sangat total dalam membuat dan menyebarkan budaya pop Korea ke negara lain. Dengan kualitas yang baik dan didukung oleh bintang yang berpenampilan menarik, produk budaya pop Korea menjadi mudah disukai oleh banyak kalangan. Pengaruh budaya pop Korea dalam kehidupan masyarakat Indonesia pun, baik disadari ataupun tidak, telah mempengaruhi banyak aspek dalam kehidupan. Sebagai contohnya adalah semakin banyak orang Indonesia yang menjadi menyukai K-Pop, tertarik untuk mengikuti drama Korea, tertarik pada fashion Korea seperti gaya rambut dan pakaian, dan bahkan banyak orang yang tertarik pada Korean way of life (Simbar,
2016).

Di Korea sendiri, tidak mudah bagi seseorang untuk menjadi bintang K-pop atau yang lebih sering dibilang "idol." Mereka harus melalui seleksi audisi yang begitu ketat, setelah itu harus melalui masa training selama bertahun-tahun sebelum akhirnya diorbitkan (debut). Selama masa training itulah banyak calon idol yang tidak tahan kemudian gugur dari persaingan industri hiburan di Korea. Banyak pula yang setelah bertahun-tahun mangikuti training tetapi tidak diorbitkan karena beberapa sebab, seperti tidak cukup menjual untuk tampil di TV. Selain berlatih menyanyi dan menari, para calon idol harus tinggal bersama selama training, hidup jauh dari keluarga, dan bersedia untuk tidak menjalin hubungan asmara selama training. Setelah debut pun, banyak aturan ketat yang harus diikuti oleh para idol karena selain menjual talenta, para idol tersebut juga menjual image yang bagus untuk para penggemar. Di Korea sendiri, jika nama seorang idol sudah tercemar oleh suatu kasus, maka masyarakat tidak mau menerima mereka dan banyak acara TV yang tidak mau memakai mereka lagi. Sehingga, perilaku dari selebriti terkenal di Korea harus selalu dikontrol oleh manajemen artisnya.

Seiring dengan maraknya budaya pop Korea yang merambah ke Indonesia, Bahasa Korea digemari oleh para remaja yang ingin lebih dekat dengan apa yang mereka sukai. Selain dari segi budaya, ketertarikan pembelajar bahasa Korea juga meningkat karena Korea Selatan telah menjalin banyak kerjasama dengan Indonesia. Pemerintah Korea Selatan juga menjanjikan kemudahan proses imigrasi seperti kemudahan pembuatan visa turis bagi pengunjung Indonesia yang ingin ke Korea Selatan (Strait times, 2018). Budaya pop Korea tidak bisa dilepaskan dari keseharian para mahasiswa di Prodi DIII Bahasa Korea, karena tidak mungkin seseorang belajar sebuah bahasa asing tanpa mempelajari budayanya. Oleh karena itu, perlu digali lebih dalam sejauh mana 
keefektifan kelas bahasa Korea dengan menggunakan media ajar budaya pop Korea seperti lagu Korea, drama Korea, dan TV show Korea yang sedang digandrungi oleh remaja di Indonesia.

\section{METODE PENELITIAN}

Metode yang digunakan dalam penelitian ini adalah metode penelitian kuantitatif. Objek penelitian yang digunakan adalah mahasiswa angkatan 2018 di program studi DIII Bahasa Korea, Departemen Bahasa, Seni, dan Manajemen Budaya, Sekolah Vokasi, UGM. Jumlah seluruh responden adalah sebanyak 27 mahasiswa. Alasan dipilihnya mahasiswa angkatan 2018 adalah karena mahasiswa angkatan 2018 adalah termasuk generasi yang lahir di tahun 2000-an. Generasi ini merupakan genrasi yang lebih melek teknologi dan lebih menyukai belajar dengan media teknologi dibandingkan generasi-generasi sebelumnya. Data dikumpulkan menggunakan metode angket dengan media google form dan responden diminta untuk melengkapi angket tersebut. Angket yang sudah dilengkapi oleh responden kemudian dianalisis dengan menggunakan analisis deskriptif presentatif. Angket digunakan untuk mengetahui latar belakang budaya pop Korea yang menjadi motivasi belajar bahasa Korea bagi mahasiswa dan pentingnya budaya pop Korea untuk mendukung pembelajaran di kelas bahasa Korea.

\section{HASIL DAN PEMBAHASAN}

Untuk belajar bahasa Korea, pembelajar dituntut untuk mempelajari huruf khas dari negara Korea, yaitu hangeul. Berbeda dengan pola kalimat bahasa Indonesia atau bahasa Inggris yang berpola subyek-predikat-obyek, pola kalimat dalam bahasa Korea adalah subyek-obyek-predikat (predikat berada di akhir kalimat). Perbedaan pola kalimat ini dirasa cukup membingungkan bagi pembelajar bahasa Korea di Indonesia yang tidak terbiasa dengan pola kalimat tersebut. Bahasa Korea juga memiliki berbagai macam partikel penanda dan kedudukan kata dalam kalimat bahasa Korea ditentukan oleh partikel penanda yang melekat pada kata tersebut. Sebagai contohnya adalah partikel penanda topik, partikel penanda obyek, partikel penanda subyek, dan partikel penanda tempat. Urutan kata dalam kalimat bahasa Korea fleksibel, namun fungsinya sebagai subjek, obyek, maupun keterangan tidak akan mengubah kedudukan dan maknanya. Dalam Bahasa Korea, harus diperhatikan tingkat kesopanan penyampaian bahasanya sehingga ada jenis bahasa Korea formal, bahasa Korea semi-formal, dan bahasa Korea informal. Predikat bahasa Korea berupa kata dasar berkonjugasi dan perubahannya menandakan keterangan waktu, tingkat kesopanan, dan situasi.

Dalam belajar bahasa Korea perlu dikuasai aspek membaca, menulis, menyimak, dan mendengar. Selain itu, untuk mendukung kompetensi lulusan, di Program Studi DIII Bahasa Korea, Sekolah Vokasi, UGM terdapat kelas tentang budaya Korea seperti Masyarakat Korea, Bisnis Korea, dan Pariwisata Korea. Dalam setiap proses pembelajaran, terdapat topik yang harus dikuasai mahasiswa. Misalnya, pada minggu pertama yang harus dikuasai adalah topik mengenai transportasi Korea, di minggu kedua belajar mengenai cuaca di Korea, dan di minggu berikutnya belajar mengenai kehidupan kampus di Korea. Untuk bisa menguasai kosakata dan tata bahasa yang diajarkan, dosen harus mampu menjelaskan mengenai budaya Korea dan mencontohkan penggunaan kalimatnya dalam kehidupan sehari-hari. Oleh karena itu, memutar video dari drama Korea atau lagu Korea sangat sering dilakukan oleh dosen agar mahasiswa semakin memahami apa yang diajarkan.

\section{Gaya Belajar Mahasiswa Prodi D3 Bahasa Korea}

Gaya belajar merupakan cara yang dianggap paling mudah bagi individu 
pembelajar untuk menyerap dan mengatur informasi yang diterima. Gaya belajar yang sesuai bagi seorang siswa dapat membuat siswa puas dengan hasil pembelajaran yang ingin dicapai (Sudjana, 2005 dalam Chania Y., 2016). Ada banyak klasifikasi mengenai gaya belajar dan beberapa kegiatan kelas yang sesuai dengan gaya belajar tersebut. Sebagai contohnya adalah apa yang disampaikan oleh Xu (2011).

"For auditory learners, these activities include interviewing, debating, participating on a panel, giving oral reports, and participating in oral discussions of written material. For Visual Learners, these activities are suggested: computer graphic, maps, graphs, charts, cartoons, posters, diagrams, text with a lot of pictures. For tactile learners, some favorite activities include drawing, playing board games, and making models. For kinesthetic learners, playing games that involve the whole body, movement activities, making models, and setting up experiments. For global learners, choral reading, recorded books, story writing, computer programs, games, group activities. For analytic learners, information presented in sequential steps, teacher directed, clear goals and requirements (Xu, 2011)."

Dalam kegiatan belajar mengajar di kelas, pembelajar dengan gaya belajar auditori suka dengan kegiatan yang melibatkan suara dengan berbicara atau mendengar. Untuk pembelajar gaya visual, mereka harus bisa melihat dan mengamati secara langsung apa yang mereka pelajari. Sedangkan pembelajar dengan gaya belajar kinestetik, memerlukan banyak kegiatan yang melibatkan banyak gerakan atau praktek secara langsung. Secara umum, pembelajar gaya kinestetik tidak tahan untuk hanya duduk diam ketika belajar. Untuk pembelajar dengan gaya belajar analitis, mereka membutuhkan instruksi yang jelas dan rinci dari pengajar. Sehingga mereka cenderung akan menemukan kesulitan jika diberi kebebasan untuk melakukan apapun yang mereka mau pelajari tanpa adanya urutan yang jelas.

Dalam penelitian ini, digunakan preferensi gaya belajar visual, auditori, dan kinestetik (Deporter \& Hernacki, 2000). Alasan digunakannya ketiga gaya belajar tersebut sebagai tolok ukur adalah karena dalam proses kegiatan belajar mengajar, preferensi siswa dapat diamati melalui alat indera. Pelajar dengan gaya belajar visual belajar melalui sesuatu yang mereka lihat, pelajar dengan gaya belajar auditori belajar dengan cara mendengar, dan pelajar dengan gaya belajar kinestetik belajar melalui gerakan, bekerja, dan menyentuh hal yang dipelajarinya. Setiap siswa memiliki ketiga gaya belajar tersebut, hanya saja satu gaya belajar biasanya lebih mendominasi.

Dari hasil angket yang telah diisi oleh mahasiswa, diperoleh data gaya belajar mahasiswa di Program Studi Diploma 3 Bahasa Korea angkatan 2018 yang dituangkan pada tabel 1. Dari tabel di atas, dapat disimpulkan bahwa prosentase terbanyak, yaitu $38 \%$ mahasiswa tidak bisa memutuskan gaya belajar apa yang mereka miliki. Salah satu penyebabnya adalah mereka memiliki gaya belajar yang merupakan kombinasi dari gaya belajar yang sudah disebutkan sebelumnya atau gaya belajar campuran. Untuk gaya belajar campuran ini, mahasiswa tidak bisa belajar dengan satu metode, melainkan dengan berbagai metode sesuai situasi yang mereka alami. Hal baik dari gaya belajar campuran adalah mahasiswa bisa dengan mudah beradaptasi dengan lingkungan belajar yang terus berubah. Misalnya ketika lingkungan berubah dari keadaan tenang ke berisik, mahasiswa dengan gaya belajar auditori akan susah untuk beradaptasi, tetapi mahasiswa dengan gaya belajar campuran bisa lebih mudah menyesuaikan diri.

Dari tabel 1 juga bisa disimpulkan bahwa dosen tidak bisa hanya memakai satu pendekatan dalam mengajar dan 
menggunakan satu media ajar untuk mengajarkan bahasa Korea. Kondisi yang banyak terjadi adalah, secara konvensional banyak dosen yang mendominasi kelas dengan terus memberi kuliah di kelas tanpa memberi waktu diskusi. Ada pula dosen yang terus menerus menyuruh mahasiswa berdisukusi tanpa ada penjelasan dan ulasan mengenai hal yang didiskusikan. Sehingga dalam setiap pertemuan di kelas, dosen perlu memberikan variasi dalam kegiatan belajar mengajar.

Tabel 1. Gaya Belajar Mahasiswa Prodi D3 Bahasa Korea

\begin{tabular}{|l|c|c|}
\hline Gaya Belajar & $\begin{array}{c}\text { Jumlah } \\
\text { Siswa }\end{array}$ & Prosentase \\
\hline Visual & 3 & 12 \\
\hline Auditori & 5 & 19 \\
\hline Kinestetik & 4 & 15 \\
\hline $\begin{array}{l}\text { Auditorial- } \\
\text { Kinestetik }\end{array}$ & 3 & 12 \\
\hline $\begin{array}{l}\text { Visual- } \\
\text { Auditorial- } \\
\text { Kinestetik }\end{array}$ & 1 & 4 \\
\hline $\begin{array}{l}\text { Tidak } \\
\text { terlihat }\end{array}$ & 10 & 38 \\
\hline Total & $\mathbf{2 6}$ & $\mathbf{1 0 0 \%}$ \\
\hline
\end{tabular}

Sebagai contohnya adalah ketika kelas menyimak, dosen tidak harus terus menyimak rekaman dari buku teks yang sudah ada, tetapi bisa membuka youtube dan memperlihatkan video yang sesuai tema. Ketika membahas mengenai berbagai dialek bahasa yang digunakan di Korea, dosen bisa membuka youtube dan secara langsung mahasiswa bisa mendengar dan melihat perbedaan dialek dari wilayah Busan, Daegu, Seoul, dan Pulau Jeju di Korea. Ketika dihadapkan pada pengajaran tata bahasa Korea yang tidak lazim dipergunakan dalam Bahasa Indonesia, dosen bisa memutarkan video dari drama Korea ketika tata bahasa tersebut digunakan dalam dialog. Sehingga mahasiswa bisa secara langsung tahu cara penggunaan tata bahasa tersebut.

\section{Peran Budaya Pop Korea dalam Pembelajaran Bahasa Korea}

Tidak bisa dipungkiri bahwa budaya pop Korea berperan penting dalam pembelajaran bahasa Korea. Seperti yang responden sampaikan bahwa $88.9 \%$ dari mereka menyukai budaya pop Korea, dan sisanya $11.1 \%$ menjawab bahwa mereka biasa saja dengan budaya pop Korea. 92.6\% responden menjawab bahwa mereka menyukai budaya pop Korea terlebih dahulu baru kemudian termotivasi untuk belajar bahasa Korea, sedangkan sisanya belajar bahasa Korea terlebih dahulu baru kemudian memiliki ketertarikan dengan budaya pop Korea. Ketika ditanyakan apakah responden mengunakan budaya pop Korea untuk belajar bahasa Korea, 96,3\% menjawab "iya" yang berarti bahwa keberadaan budaya pop Korea tidak lepas dari proses pembelajaran bahasa Korea. Beberapa budaya pop Korea yang paling disukai oleh responden adalah K-Pop (48.1\%), KDrama (33.3\%), K-Movie (3.72\%), Puisi Korea (3.72), Novel Korea (3.72), Program TV Show (3.72), K-Hiphop dan $\mathrm{K}-\mathrm{RnB}(3.72 \%)$. Ketika ditanya apakah seharusnya lebih banyak kegiatan belajar bahasa Korea menggunakan bahasa Korea, $65.4 \%$ responden menjawab iya dan sisanya (34.6\%) menjawab tidak perlu.

Apakah Anda menyukai budaya pop Korea? (contoh: lagu, drama, film, sastra)

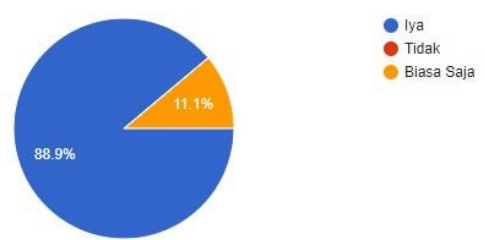

Gambar 1. Ketertarikan Mahasiswa terhadap Budaya Pop Korea

\section{Belajar Bahasa Korea Menggunakan Budaya Pop Korea}

Responden dengan berbagai gaya belajar yang berbeda menggunakan budaya pop Korea untuk menunjang kegiatan belajar Bahasa Korea yang mereka lakukan. Beberapa mahasiswa belajar dengan cara mengartikan lagu 
Korea yang didengar, hal tersebut bisa membuat mereka belajar kosakata dan ungkapan baru dalam bahasa Korea. Cara lain yang dilakukan adalah dengan cara menyanyikan lagu Korea sambil membaca lirik lagu tersebut, yang dianggap efektif untuk belajar pelafalan Bahasa Korea. Ketika menonton drama Korea, mahasiswa mendengar kata yang diucapkan dan melihat artinya di subtitle yang dituliskan, atau belajar dengan menonton drama tanpa subtitle sama sekali. Belajar pelafalan dan ungkapan bahasa Korea juga efektif dengan cara menirukan kata-kata yang diucapkan di drama Korea, jika ada kosakata yang baru, responden mencatat dan mencari artinya kemudian. Selain dengan media lagu dan drama Korea, beberapa responden belajar bahasa Korea dengan melihat Youtube. Melalui media Youtube, responden bisa memilih sendiri konten yang mereka inginkan untuk belajar, baik itu tentang kosmetik Korea, konten makan dengan bahasa Korea, atau cerita sehari-hari dari orang Korea di akun Youtube-nya.

Apakah Anda menggunakan budaya pop Korea untuk belajar Bahasa Korea?

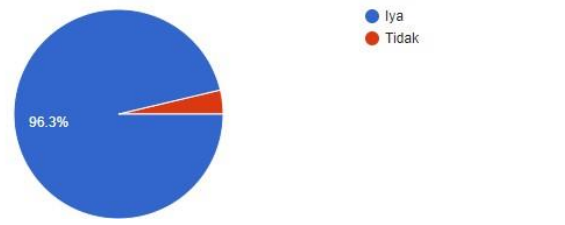

Gambar 2. Penggunaan Budaya Pop Korea saat Belajar Bahasa Korea

Melalui Youtube atau media lain, responden bisa juga melihat acara TV Korea. Mereka menonton acara TV tersebut tanpa subtitle sehingga bisa melatih kemampuan menyimak percakapan dalam bahasa Korea. Jika ada tata bahasa yang baru saja dipelajari di kelas, maka responden akan lebih mudah memahami penggunaan tata bahasa tersebut dari apa yang sudah mereka tonton. Seorang responden menyampaikan bahwa menonton drama Korea membuatnya lebih percaya diri untuk berlatih kemampuan berbicara. Melalui drama Korea tersebut, responden bisa benar-benar paham bagaimana sebuah kosakata atau tata bahasa dalam bahasa Korea digunakan. Responden juga bisa belajar pelafalan bahasa Korea dengan menirukan gaya bicara dan kata-kata yang diucapkan oleh tokoh di dalam drama Korea tersebut.

Dalam kelas non-Bahasa Korea, penggunaan media video juga efektif untuk meningkatkan pemahaman pemberlajar. Misalnya pada kelas Masyarakat Korea, sulit bagi dosen untuk menjelaskan pakaian tradisional yang dipakai pada dinasti Jeoson atau Dinasti Sylla hanya dengan metode ceramah. Dengan memutar video mengenai sejarah Korea, maka mahasiswa bisa langsung memahami tanpa perlu membayangkan tentang kehidupan orang Korea satu abad yang lalu. Ketika teknologi sudah sangat cangih seperti hari ini, maka pemanfatan teknologi adalah hal yang selayaknya dilakukan untuk membantu kehidupan. Selain itu, mahasiswa saat ini yang merupakan generasi milenial akan lebih memberi apreasiasi pada materi kuliah yang disampaikan melalui pemanfaatan teknologi.

Tidak hanya mahasiswa yang diberi kewajiban untuk memperlajari teknologi, dosen pun senantiasa harus siap dengan perkembangan teknologi dan mau belajar untuk tetap bisa memberikan yang terbaik bagi anak didiknya.

\section{Kegiatan Kelas dengan Menggunakan Budaya Pop Korea}

Selain menceritakan mengenai bagaimana responden belajar bahasa Korea menggunakan budaya pop Korea, responden juga memberikan beberapa pendapat yang berkaitan dengan kegiatan kelas dengan memakai budaya pop Korea yang dirasa efektif dalam proses belajar bahasa Korea. Untuk kelas menyimak, 
beberapa menyarankan untuk melihat film Korea tanpa subtitle atau bisa dengan mendengar sebuah lagu Korea, lalu menerjemahkan dan menganalisis isi lagu Korea tersebut dengan juga mempertimbangkan aspek budaya Korea yang tersirat dalam lagu. Mendengar lagu Korea dengan metode missing lyrics juga dianjurkan oleh beberapa responden. Metode missing lyrics adalah metode dengan mengisikan lirik yang kosong di kertas jawaban. Mahasiswa bisa mengisi lirik yang kosong tersebut jika mereka bisa dengan seksama mendengarkan lagu yang diputar.

Apakah seharusnya lebih banyak aktifitas belajar bahasa Korea di kelas menggunakan budaya pop Korea?

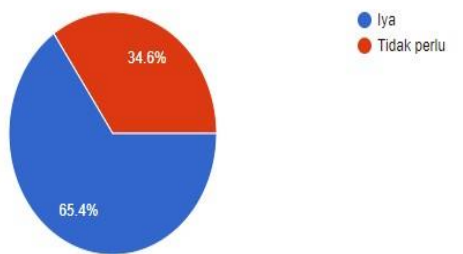

Gambar 3. Pendapaat Mahasiswa tentang penggunaan budaya Pop Korea di Kelas

Untuk pembelajaran tata bahasa, disarankan untuk memutar video dari drama atau acara TV Korea yang memperlihatkan penggunaan tata bahasa yang baru dipelajari tersebut. Untuk melatih kemampuan menulis dan juga menyimak dalam bahasa Korea, bisa diputarkan video pendek dalam bahasa Korea yang sederhana, sehingga mudah dipahami oleh mahasiswa. Setelah melihat video pendek, mahasiswa diminta untuk menuliskan kembali isi video tersebut dan pendapat mereka terkait isinya dalam bahasa Korea. Kelas juga bisa menjadi lebih menarik jika diselingi dengan permainan Korea agar suasana kelas tidak membosankan.

Meskipun mayoritas responden setuju dengan penggunaan budaya Korea dalam proses pembelajaran, beberapa responden menyatakan ketidaksetujuannya. Contohnya adalah tidak semua pembelajar setuju dengan belajar menggunakan lagu Korea. Meskipun banyak yang berpendapat bahwa belajar dari lirik lagu dan membahas isinya adalah cara yang bagus, tetapi selera musik setiap mahasiswa berbeda, sehingga mahasiswa yang tidak menyukai lagu yang diputar, tidak tertarik dengan metode tersebut. Responden lain menyatakan bahwa tidak perlu memakai drama Korea untuk belajar bahasa Korea di kelas karena dikhawatirkan mahasiswa akan lebih fokus pada cerita di drama Korea tersebut dibandingkan dengan mempelajari materi kuliah yang diajarkan di kelas. Selain itu, hal tersebut bisa mengubah persepsi mahasiswa dari yang awalnya menonton drama Korea untuk kesenangan berubah menjadi menonton drama Korea demi tugas yang merupakan sebuah beban. Salah satu responden menyampaikan bahwa dia tidak bisa fokus belajar di lingkungan yang tidak tenang. Jika menggunakan K-pop dan K-Drama untuk belajar bahasa Korea, dikhawatirkan suasana kelas akan berisik karena mahasiswa terlalu bersemangat ketika melihat idola mereka muncul di layar. Penggunaan lirik lagu dan puisi Korea dirasa lebih efektif jika wajah dari idol atau bintang yang mereka sukai tidak ditampilkan agar suasana kelas tetap tenang.

Harus disadari bahwa dalam kegiatan belajar mengajar mengajar, dosen tidak bisa menyenangkan semua mahasiswa karena setiap mahasiswa memiliki gaya belajar yang berbeda-beda. Yang menjadi kewajiban pendidik adalah menyampaikan materi ajar dengan sebaik mungkin menggunakan metode dan media ajar yang paling sesuai dengan mahasiswa. Dengan mahasiswa yang memiliki gaya belajar campuran, mau tidak mau dosen harus menggunakan kegiatan belajar yang bervariasi agar suasana kelas tetap dirasa efektif untuk proses belajar mengajar, tidak hanya untuk mahasiswa tetapi juga untuk dosen itu sendiri. 


\section{KESIMPULAN}

Dari penelitian yang sudah dilakukan, dapat disimpulkan bahwa mahasiswa Prodi D3 Bahasa Korea angkatan 2018 dapat secara umum dikatakan bahwa mereka memiliki gaya belajar campuran. Sehingga perlu sebuah metode pengajaran yang bervariasi. Mahasiswa juga menyampaikan bahwa mereka menyukai belajar bahasa Korea yang diselingi dengan permainan, pemutaran video, dan mendengarkan lagu Korea. Walaupun banyak yang setuju dengan penggunaan budaya pop Korea dalam kegiatan kelas, beberapa mahasiswa tidak setuju karena hal tersebut dianggap bisa mengganggu konsentrasi belajar di kelas, sehingga dosen harus memberikan variasi kegiatan belajar, tidak terus menggunakan budaya pop Korea tetapi diselingi dengan kegiatan yang membutuhkan ketenangan agar setiap mahasiswa bisa merasakan efektifitas dari kegiatan yang dosen lakukan. Dalam proses belajar mengajar, seorang pengajar diharuskan menyesuaikan kegiatan kelasnya dengan gaya belajar dari pelajarnya. Hal tersebut dimaksudkan agar tujuan pembelajaran bisa dicapai secara efektif. Dalam pembelajaran bahasa Korea, banyak mahasiswa yang belajar bahasa Korea karena pada awalnya mereka tertarik pada budaya pop Korea seperti lagu Korea, drama Korea, dan acara TV Korea. Sehingga dengan memakai budaya pop Korea dalam proses belajar mengajar Bahasa Korea, mahasiswa akan lebih mudah menyerap materi yang diajarkan.

\section{DAFTAR PUSTAKA}

Admin GTK Madrasah. (2019). Pola Pendidikan Yang Tepat Bagi Generasi $\mathrm{Z}$ dan Generasi Alfa. Diakses dari https://gtkmadrasah.kemenag.go.id/20 19/07/03/pola-pendidikan-yang-tepatbagi-generasi-z-dan-generasi-alfa/ September 2019.

Akram Awla, H. (2014). Learning Styles and Their Relation to Teaching Styles. International Journal of Language and Linguistics, 2 (3), 241. https://doi.org/10.11648/j.ijl1.2014020 3.23

Bire, A.L. et.al. (2014). Pengaruh Gaya Belajar Visual. Auditorial, dan Kinestetik Terhadap Prestasi Belajar Siswa. Jurnal Kependidikan. 44 (2): 168-174.

Bobbi DePorter \& Mike Hernacki. (2000). Quantum Learning. Edisi Revisi. Kaifa, Bandung.

Chania, Y. Et.al. (2016). Hubungan Gaya Belajar Dengan Hasil Belajar Siswa Pada Pelajaran Biologi Kelas X SMAN 2 Sungai Tarab Kabupaten Tanah Datar. Journal of Sainstek 8 (1): 77-84.

Harsono. Strategi Belajar. Pusat Pengembangan Pendidikan Universitas Gadjah Mada.

Haynes, J. Teach to students' learning styles. Diakses dari http://www.everythingesl.net/inservic es/l earningstyle.php

Melisa. (2016). Gaya Belajar Generasi Z. Majalah 1000 guru.net. Diakses dari http://majalah1000guru.net/2016/08/g aya-belajar-generasi-z/September 2019.

Mofareh, Al Qahtani (2015). The importance of vocabulary in language learning and how to be taught. International Journal of Teaching and Education, Vol. III (3), pp. 21- 34., DOI: 10.20472/TE.2015.3.3.002

Muhtadi, A. (2006). Karakteristik gaya belajar mahasiswa ditinjau dari preferensi sensori dan lingkungan. Jurnal TEKNODIKA, 4 (7), 1-21.

Pratama. H. C. (2012). Cyber Smart Parenting. Bandung. PT. Visi Anugerah Indonesia.

Rani, S. P. (2016). Korean Wave Sebagai Salah Satu Pendukung Nation Branding yang dilakukan oleh Korea Selatan. Universitas Indonesia.

Simbar, F. K. (2016). Fenomena Konsumsi Budaya Korea Pada Anak Muda Di Kota Manado. Holistik, (18), 1-20.

Strait Times. (2018). Korsel-Indonesia Sepakat Kerjasama Ekonomi dan 
Pertukaran Masyarakat. Diakses dari https://www.matamatapolitik.com/kor ea-selatan-indonesia-sepakattingkatkan-kerjasama-ekonomi-danpertukaran-masyarakat.

Suryani, N. P. E. (2015). Korean Wave sebagai Instrumen Soft Power untuk Memperoleh Keuntungan Ekonomi Korea Selatan. Global. Jurnal Politik Internasional, 16 (1), 69-83. https://doi.org/10.7454/global.v16i1.8
Syarfuni, \& Verawati. (2017). Analisis Karakteristik Gaya Belajar Mahasiswa Pendidikan Bahasa Inggris Angkatan 2016 Stkip Bina Bangsa Getsempena Banda Aceh. Genta Mulia VIII (1), 75-83.

$\mathrm{Xu}, \mathrm{W}$. (2011). Learning styles and their implications in learning and teaching. Theory and Practice in Language Studies, 1 (4),413-416. https://doi.org/10.4304/tpls.1.4.413416 